\title{
Dyslipidemia and Associated Factors Among Adult Patients on Antiretroviral Therapy in Armed Force Comprehensive and Specialized Hospital, Addis Ababa, Ethiopia
}

This article was published in the following Dove Press journal:

HIVIAIDS - Research and Palliative Care

\author{
Adnan Kemal ${ }^{1, *}$ \\ Melese Sinaga Teshome ${ }^{2, *}$ \\ Mohammed Ahmed (iD ${ }^{3}$ \\ Meseret Molla' \\ Tabarak Malik (iD) \\ Jemmal Mohammed ${ }^{5}$ \\ Kalkidan Hassen Abate ${ }^{2, *}$ \\ 'Department of Public Health, College of \\ Health Science, Defense University, Addis \\ Ababa, Ethiopia; ${ }^{2}$ Department of \\ Nutrition and Dietetics, Jimma University, \\ Jimma, Ethiopia; ${ }^{3}$ Department of Public \\ Health, College of Health Science, \\ Woldia University, Woldia, Ethiopia; \\ ${ }^{4}$ Department of Biochemistry, College of \\ Medicine and Health Sciences, University \\ of Gondar, Gondar, Ethiopia; \\ ${ }^{5}$ Department of Ophthalmology, Jimma \\ University, Jimma, Ethiopia \\ *These authors contributed equally to \\ this work
}

Background: The development of antiretroviral drugs and subsequent access to combined antiretroviral therapy contributed to the decline in morbidity and mortality rates associated with acquired immune deficiency syndrome, resulting in an increased life expectancy and improved quality of life for people living with human immunodeficiency virus. However, a cluster of metabolic derangements such as dyslipidemia is increasing, especially for those on antiretroviral therapy. Limited studies were done on the prevalence of dyslipidemia and its associated factors among adult patients on antiretroviral therapy in Ethiopia which demand the conduct of the present investigation entitled on the prevalence of dyslipidemia and its associated factors among adult patients on antiretroviral therapy in Armed Force Comprehensive and Specialized Hospital Addis Ababa, Ethiopia, 2018.

Methods: Institution-based cross-sectional study design was employed between March and April 2018. Systematic sampling method was used to select 353 study participants. Pretested stepwise approach of the World Health Organization questionnaire (WHO Stepwise), document review, anthropometric measurements, and laboratory analysis were used to collect data on different variables under the study. Collected data were entered in Epidata version 3 and analyzed by SPSS version 21.

Results: The prevalence of dyslipidemia among study participants was $74.8 \%$. Female participants were twice and half at risk of developing dyslipidemia compared to males $(\mathrm{AOR}=2.38$; 95\% CI: 1.15, 3.66). Similarly, compared to those attended college level of education, not attended formal education ( $\mathrm{AOR}=0.19 ; 95 \% \mathrm{CI}$ : $0.05,0.66)$, and having primary/secondary educational level (AOR $=0.33$; 95\% CI: 0.16, 0.66) showed lower odds to develop dyslipidemia. Furthermore, WHO clinical stage II (AOR $=0.35 ; 95 \%$ CI: $0.14,0.92)$, stage III (AOR $=0.25 ; 95 \%$ $\mathrm{CI}: 0.10,0.64)$, duration on ART $(\mathrm{AOR}=1.01 ; 95 \% \mathrm{CI}: 1.001,1.02)$, and $\mathrm{BMI}(\mathrm{AOR}=1.13 ; 95 \%$ CI: $1.06,1.23)$ were significantly associated with dyslipidemia.

Conclusion: There exists a high prevalence of dyslipidemia among study participants. Sex, educational status, WHO clinical stage, duration on ART, and BMI were significantly associated factors for dyslipidemia. Intervention strategies including the identified factors are demanded in the setting.

Keywords: dyslipidemia, HIV/AIDS, antiretroviral therapy, Ethiopia

\section{Background}

Correspondence: Melese Sinaga Teshome; Adnan Kemal

Email sinmele@gmail.com;

adnankemale@gmail.com
HIV/AIDS is one of the most destructive diseases humankind has ever faced. It brings with it profound social, economic and public health consequences. It has become one of the world's most serious health and development challenges. ${ }^{1}$ 
Sub-Saharan Africa, home of $12 \%$ of the global population, resides disproportionately $70 \%$ of the global burden of HIV infection while only $79 \%$ had access to Antiretroviral therapy. With more than thirty years of the HIV epidemic, there is still no cure or an effective vaccine; however, there have been major advances in treating HIV using antiretroviral therapy (ART). ${ }^{2}$ Despite ART has improved and prolonged life, it has been associated with a cluster of metabolic derangements. These abnormalities include dyslipidemia, atherosclerosis, and insulin resistance. $^{3}$ Dyslipidemia refers to elevated levels of lipids and cholesterol in the blood, elevated low-density lipoprotein cholesterol (LDL), total cholesterol (TC), triglycerides (TG), and or low levels of high-density lipoprotein cholesterol (HDL). ${ }^{4}$

Dyslipidemia on ART taking HIV patients can be caused through four mechanisms; viral particle competition on lipid metabolism receptors including CRABP-1 - cellular retinoic acid binding protein and LDL receptor-related protein (LRP), inhibition of the activity of the plasmatic lipoprotein lipase, upsurge the levels of liver Apolipoprotein B (Apo B) and deterring the function of glucose transporter type 4 (GLUT4). ${ }^{5}$ These pathogenic processes can be reflected in patients with hematologic and anthropometric indices which can be detected using anthropometric, hematologic and dietary assessments. ${ }^{6}$

Globally, the occurrence of dyslipidemia in HIV-seropositive patients receiving ART has been estimated to be between $20 \%$ and $80 \%{ }^{7,8}$ The highest incidence was hypertriglyceridemia, which is seen in the majority of HIV cases (40-80\%), followed by hypercholesterolemia (10-60\%), low HDL level (20-40\%), and hyperglycemia (5-30\%). ${ }^{9}$ Dyslipidemia associated with increased risk of cardiovascular disease occurs in about $70 \%$ of HIV infected patients receiving antiretroviral therapy, it is a powerful risk factor for coronary heart disease and patients with established CHD have a 10 -year risk of having a CHD event such as cardiac death or myocardial infarction that is $>20 \%$ ( $>2 \% /$ year). ${ }^{10}$

The proportion of dyslipidemia in African countries was not even. An earlier study in south Ethiopia showed 82.3\% of dyslipidemia among patients on ART and $76.9 \%$ pre-ART patients. ${ }^{11}$ Another study was done in Blackline hospital, Addis Ababa, Ethiopia, also showed that higher proportion of dyslipidemia among antiretroviral treatment group (80\%) compared to antiretroviral treatment naïve groups $(57.7 \%){ }^{12}$ A study in South Africa reported $90.0 \%$ and $85 \%$ dyslipidemia prevalence among patients on ART-naive and ART, respectively. ${ }^{7}$ Similarly, in Zimbabwe, more than $60 \%$ ART naïve and ART-experienced patients had some form of dyslipidemia either at baseline or at follow-up. ${ }^{13}$

However, there exists a new global effort to increase the number of people who have access to HIV treatment in recent years, particularly in resource-poor countries. ${ }^{14,15}$ A major milestone was achieved in 2016, for the first time, it was found that more than half $(53 \%)$ of all people living with HIV have access to life-saving treatment. If this level of treatment scale-up continues, it is estimated that the world will meet its global target of 30 million people on treatment by 2020 , which may increase the incidences of the NCDs in the future. ${ }^{6,16}$

Several studies showed that different risk factors contributed for dyslipidemia and includes, duration on ART, age, sex, high BMI, low CD4 counts, cigarette smoking, alcohol consumption, physical inactivity, dietary habits, and depression are the major risk factors. ${ }^{14-18}$

Despite these facts, the prevalence of dyslipidemia in resource-limited settings has not been well characterized and the current World Health Organization (WHO) Antiretroviral therapy (ART) guidelines do not include lipid monitoring in patients on ART. In addition, evidence in support of dyslipidemia associated with ART in SubSahara African countries are scarce. ${ }^{11}$ Also in our countries, lipid profile measurements at baseline currently not part of routine care which is an important parameter to increase survival and improve treatment outcome. ${ }^{12}$

Understanding the context-specific factors for ARTassociated dyslipidemia and its potential implications for HIV-infected patients is critical to the design of effective interventions to combat the metabolic and cardiovascular disease's effects of dyslipidemia. ${ }^{4}$ However, there were few studies done on the prevalence of dyslipidemia and its associated factors among adult patients on Antiretroviral therapy in Ethiopia in general. Therefore, the present study was designed to assess the prevalence of dyslipidemia and its associated factors among adult patients on Antiretroviral therapy in Armed Force Comprehensive and Specialized Hospital, Addis Ababa, Ethiopia.

\section{Methods}

\section{Study Setting and Design}

Institutional-based cross-sectional study design was conducted from March to April 2018 at Armed Force Comprehensive and Specialized Hospital, Addis Ababa, is the capital city of Ethiopia, the seat for African Union and economic commission for Africa. The hospital has been 
delivered health services to the Defense forces; civilians in the Ministry of Defense and their dependents as well as public patients referred by other specialty hospitals and public-private patients. The hospital launched a free ART program at the end of 2003. The total numbers of subjects ever enrolled for HIV care were 4329 of whom 4053 were adults. From the total HIV care attendants; 2263 adults were currently on ART in the hospital; from this, 1750 subjects came for follow up during the study period.

All adult PLWHA who came for ART follow up at Armed Force Comprehensive and Specialized Hospital was the source of population. Those randomly selected individuals who came for ART follow up to the ART clinic during the study period were the study population. An individual's living with HIV/AIDS, aged $\geq 18$ years who had been receiving ART for at least 6 months or more, able to communicate and provide informed consent were included in the study and, Participants who had receiving lipid-altering therapies, pregnant women, physically deformed individuals were excluded from the study.

\section{Sample Size Determination and Sampling Procedure}

The sample size was calculated by using a single population proportion formula by taking proportion dyslipidemia among PLWHA 63.6\%, which is done in Addis Ababa (35),95\% CI, 5\% Margin of error and by adding 5\% nonresponse rate the minimum final sample size becomes 374. The systematic sampling method was employed to select 353 study participants. To select individual study participants, we have determined the value of the interval (k). $K=1750 / 353=4.957$ which were approximately 5 . Then, a sampling frame was prepared based on patient order when coming to the hospital for follow up. After that, the random start was randomly selected from the first 1-5 study participants, and then the data were collected and continued every 5 th study participant.

\section{Data Collection Instrument and Procedures}

WHO STEPS questionnaire was used to collect data. Question-related with chat chewing, depression, and individual dietary diversity score were added to supplement the WHO STEPS. And also document review was done for WHO stage during ART initiation, baseline CD4 count, viral load count, type of ART regimen and duration on ART. The questionnaire was first written in English, and then translated into Amharic and back to English by linguistic experts, and it was tested prior to use.

A total of nine research teams (4 ART nurses, 1 public health expert, 2 laboratory technicians, and 2 lab technologists) were used to collect data on socio-demographic characteristics, clinical, behavioral, anthropometric, blood pressure and lipid profile measurements. A supervisory team (1 public health expert and 1 lab technologist) including the principal investigator were in place during the data collection. Both the interviewers and supervisors were trained for two days on objective of the study, methods on how to collect data and interviewing approach, anthropometric measurement, biochemical measurement, and blood pressure measurement.

\section{Anthropometry Measurement Procedures}

Anthropometric measurement data such as weight, height, waist and hip circumference were collected by ART trained nurses by using the calibrated equipment. Weight was measured for all the study participants using the SECA 704 medical weighing scale. Participants were asked to remove their heavy outer garments and shoes. The participants were stands in the center of the platform. The weight was recorded to the resolution of the scale (nearest $0.1 \mathrm{~kg}$ ). Height also measured for all the study participants using the SECA 213 height meter. Participants were asked to remove their shoes, and hair ornaments. The participants were asked to stand with his/her back to the height rule. The back of the head, shoulder, buttocks, calves, and heels was touched the upright position with feet together. The top of the external auditory meatus (ear canal) was in line with the inferior margin of the bony orbit (cheekbone). The participant was asked to look straight (Frankfurt plane) so that the line of sight was perpendicular to the body. Finally, the height was recorded to the resolution of the height rule (nearest $0.1 \mathrm{~cm}$ ). ${ }^{19}$

Body mass index is a summary measure of an individual's height and weight, calculated by dividing a person's weight in kilograms by the square of their height in meters. Waist circumference was measured at the horizontal plane that corresponds with the mid-point between the anterior superior iliac spine and the lower costal margin at the midclavicular line. Also, hip circumference measurement was done for participants by using a SECA $200 \mathrm{~cm}$ tape measure. Tape measures were tagged with a barcode and replaced periodically when the maximum number of 
measurements had been reached. Participants were required to stand with feet facing directly forward and shoulder-width apart and with arms folded across their chest. The SECA measuring tape which is recorded in centimeters was placed to the widest part of the hips for hip circumference measurement. We used the European cut off point to interpret the waist to hip circumference ratio measurement for the Sub-Saharan African People according to World Health Organizations (WHO) and International Diabetes Federation (IDF) recommendations. According to the above guidelines, the range of abnormal waist to hip circumference ratio of male and female are $\geq 94 \mathrm{~cm}$ and $\geq 80 \mathrm{~cm}$, respectively. ${ }^{20}$ To improve the reliability of all anthropometric measurements, two readings were taken and the average of the two readings was recorded as the final measurement of the respondent. Calibration of SECA 704 weight meter, SECA 213 height meter, and SECA $200 \mathrm{~cm}$ tape measure performed at the beginning of the day.

\section{Blood Pressure Measurements}

Blood pressure (BP) was measured using a standard adult arm cuff of mercury type sphygmomanometer after $5 \mathrm{~min}$ rest in the clinic by the nurses working in the ART clinic. To improve the reliability of measurement, three readings were taken with 5 min interval and the average of the three readings was recorded as the final BP of the patient. But, if the difference between the two readings were greater than $5 \mathrm{mmHg}$, a third measurement was taken and recorded as the final BP of the patient. $^{21}$

\section{Laboratory Test}

Fasting Blood was collected and analyzed by qualified laboratory technologists for biochemical measurements. The study subjects were requested to return to the clinics to provide fasting blood samples for blood glucose, lipid profile and current CD4 count measurements in the next day in case if they were eaten and the test was done in next morning. Once sufficient blood $(4 \mathrm{~mL})$ was collected, triglyceride and cholesterol levels were evaluated using the enzymatic method. HDL-C was measured using selective precipitation of the low and very-low-density lipoproteins (LDL and VLDL). LDL cholesterol was measured using the preparative ultracentrifuge. After centrifugation, LDL was measured in the supernatant, using the enzymatic method. All measurements were analyzed in the COBAS MIRA PLUS spectrophotometer (Roche
Diagnostics) equipped with calibration filters and DIASYS serum control.

\section{Depression Measurement}

Twenty-one items Beck inventory depression scale was used to measure the depression status of the participants.

\section{Data Processing and Analyses}

The data were collected, cleaned, checked for completeness and consistency manually. It was coded and entered into Epi-data Version 3.1. It was exported to SPSS (Version 21.0) for further cleaning and statistical analysis. Descriptive statistics such as frequency, percentage, mean and standard deviation were used to describe characteristics of the study population. Bivariate analyses were done, a variable of interest and all covariate variables which had an association with the outcome variables at a $p$-value of less than 0.25 were selected for multivariate analyses. Multivariate logistic regression models were used to isolate independent predictors of dyslipidemia two-sided Pvalue $<0.05$ with $\mathrm{AOR}$ of $95 \%$ CI was considered to declare statistical significance associations. HosmerLemeshow test and multicollinearity were checked and problems were not found.

\section{Data Quality Assurance}

Data collectors and supervisors were trained for two days. Training of data collectors was mainly focused on the relevance of the study, the objective of the study, about the confidentiality of the information, informed consent and interview technique and how to explain relevance and significance of the study for study participants. For laboratory and physical measurement, method and time of calibration for instruments, the way of physical measurements and data recording were delivered. Instruments calibration was done at the beginning of each examining day. The principal investigator and supervisors closely followed the data collection process. A pretest was done among $5 \%$ of the total sample size in Air Force Hospital. Before the real anthropometric data collection, a standardization exercise was performed during the training to capture the technical error of measurement (TEM). All laboratory activities were done strictly following standard operational procedures (SOPs) and laboratory calibrator was traceable to International Federation of Clinical Chemistry and Laboratory Medicine (IFCC), National Institute of Standards and Technology (NIST) Centers for Disease Control and Prevention (CDC, USA) and 
American Association for Clinical Chemistry (AACC). Data were coded and entered into a computer for analysis.

\section{Ethical Consideration}

Ethical clearance was obtained from the Institutional Review Board of the Institute of Health, Jimma University, and then permission was obtained from Armed Force Comprehensive and Specialized Hospital review board and ART clinic head. The participants recruited into this study after patient confidentiality, benefits and risks to participating patients, justice, rights, and respect were addressed; were willing to participate in the study; and signed an informed consent. A thumbprint or signature was used on the consent form. If the participants were diagnosed with dyslipidemia, fasting glucose impairment and increased blood pressure, he/she was linked to the hospital for chronic care, proper treatment and follow up of this disease as well coincide with ART. Every laboratory investigation was done according to the requirement of the patient. Health education on risk factors, consequences and complications were provided to all of the participants after the compilation of data collection. This study was conducted in accordance with the Declaration of Helsinki.

\section{Results}

\section{Socio-Demographic Characteristics of Study Subjects}

A total of 353 HIV-infected patients who were on ART enrolled in the study, yielding a response rate of $94.13 \%$. In this study, the age range of participants spans from 18 to 76 years. The mean age was $44.2( \pm 9.016)$ years. More than half, 202 (57.2\%) participants were male. Regarding ethnicity, $161(45.6 \%)$ of participants were Amhara. About, 248 (70.3\%) of study participants were married. Considering education, 205 (58.1\%) of them attended primary/secondary school. As regards to occupation, 150 $(42.5 \%)$ of the participant were an employee (Table 1).

\section{Clinically Related Factors}

During ART initiation, percentage of the study participants found in WHO clinical stage II, stage III, stage IV, and stage I were $33.1 \%, 30.9 \%, 19.8 \%$, and $16.1 \%$, respectively. Duration on ART among participants ranged from 12 up to 173 months with a mean of $102.4( \pm 38.20)$. From the sample, $320(90.7 \%)$ of them used a combination of 2NRTIs and 1NNRTIs. From this more than half, 222 $(62.9 \%)$ of participants were on treatment TDF containing NRTIs while 215 (60.9\%) were on EFV-based regimen.
About, 12 (3.4\%) of participants were used only NRTI and $21(5.9 \%)$ were on ATV/r-based 2nd line ART regimen. The mean baseline CD4 count was $182.6( \pm 144.2)$ and the mean of the current CD4 count was 515.4 ( \pm 231.7$)$. Also, $320(90.7 \%)$ participants had viral load count less than $\leq 1000$ (Figure 1).

\section{Behavioral- and Metabolic-Related Factors}

The proportion of current cigarette smoking, alcohol intake, and chat chewing were 13 (6.7\%), 131 (37.1\%) and $12(3.4 \%)$ respectively. The mean dietary diversity score of our study participants was $4.85( \pm 1.43)$, while nearly half of the participants achieved $158(44.8 \%)$ below the mean. A proportion of participants with minimal, mild and moderate/severe depression were 203 (57.5\%), 85 (24.1\%) and $65(18.4 \%)$, respectively. A proportion of hypertension and waist circumferences above normal among participants were 135 (38.2\%) and 187 (53.0\%) correspondingly. The proportion of underweight, normal, overweight and obese were 48 (13.6\%), 198 (56.1\%),80 (22.7\%) and 27 (7.6\%), respectively, with the mean BMI $23.17( \pm 4.094) \mathrm{kg} / \mathrm{m}^{2}$. The FBS level of the study participants was $108.55( \pm 48.879) \mathrm{mg} / \mathrm{dl}$ (Table 2).

\section{Dyslipidemia and Characteristics of Lipid Profiles}

Two hundred sixty-four (74.8\%) of study participants had at least one laboratory abnormality, which is compatible with a diagnosis of dyslipidemia. From those who had dyslipidemia, 105 (29.7\%) of them had single lipid abnormality, 92 (26.1\%) had double lipid abnormality, 57 (16.1\%) had triple lipid abnormality and $10(2.8 \%)$ had quadruple lipid abnormality. From the total participants, the prevalence of TC $\geq 200 \mathrm{mg} / \mathrm{dl}$ were 162 (45.9\%) with mean TC 199.28 ( \pm 46.32), LDL-c $\geq 130 \mathrm{mg} / \mathrm{dl}$ was $110(31.2 \%)$ with wean LDL-c 117.61 ( \pm 56.42), TG $\geq 150 \mathrm{mg} / \mathrm{dl}$ was 102 (28.9\%) with mean TG $165.37( \pm 78.98)$ and the prevalence of HDL-c $<40 \mathrm{mg} / \mathrm{dl}$ for males and $<50 \mathrm{mg} / \mathrm{dl}$ for female, was 126 (35.7\%). Thirty-Five $(72.9 \%)$ of dyslipidemia patients had ART duration of $<59$ months. About, 64 (66.7\%) of dyslipidemic patients had ART duration between 60-107 months, and $165(78.9 \%)$ of them were $>107$ months (Figure 2).

\section{Factors Associated with Dyslipidemia Bivariate Binary Logistic Regression Analysis}

During bivariate analysis, factors such as being female sex, age, educational states, WHO clinical stage, current 
Table I Socio-Demographic Characteristics of Study Subjects Among Patients Living with HIVIAIDS at Armed Force Comprehensive and Specialized Hospital, Addis Ababa, Ethiopia Between March and April 2018 ( $n=353)$

\begin{tabular}{|c|c|c|c|c|}
\hline \multirow[t]{2}{*}{ Variables } & \multirow[t]{2}{*}{ Category } & \multirow[t]{2}{*}{ Total (\%) } & \multicolumn{2}{|c|}{ Dyslipidemia } \\
\hline & & & Yes (\%) & No (\%) \\
\hline \multirow[t]{2}{*}{ Sex } & Female & 151 (42.8) & $120(79.5)$ & $31(20.5)$ \\
\hline & Male & $202(57.2)$ & I44 (7I.3) & $58(28.7)$ \\
\hline \multirow[t]{3}{*}{ Age (years) } & \multicolumn{4}{|l|}{ Mean age: $44.2( \pm 9.016)$} \\
\hline & $\leq 40$ & 109 (30.9) & $63(57.8)$ & $37(42.2)$ \\
\hline & $>40$ & $244(69.1)$ & $192(78.7)$ & $52(21.3)$ \\
\hline \multirow[t]{5}{*}{ Ethnicity } & Oromo & $79(22.4)$ & $58(73.4)$ & $21(26.6)$ \\
\hline & Amhara & $161(45.6)$ & II 4 (70.8) & $47(29.2)$ \\
\hline & Tigray & $91(25.8)$ & $73(80.2)$ & $18(19.8)$ \\
\hline & Gurage & $12(3.4)$ & II (9I.7) & I (8.3) \\
\hline & Others & $9(2.5)$ & $8(88.9)$ & I (II.I) \\
\hline \multirow[t]{3}{*}{ Educational status } & No formal education & $50(14.2)$ & $4 \mathrm{I}(82.0)$ & $9(18.0)$ \\
\hline & Primary/Secondary & $205(58.1)$ & 149 (72.7) & $56(27.3)$ \\
\hline & College/above & $98(27.8)$ & 74 (75.5) & $24(24.5)$ \\
\hline \multirow[t]{5}{*}{ Occupational status } & House wife & $50(14.2)$ & $36(72.0)$ & $14(28.0)$ \\
\hline & Employer & $150(42.5)$ & $112(74.7)$ & $38(25.3)$ \\
\hline & Merchant & $19(5.4)$ & $15(78.9)$ & $4(21.1)$ \\
\hline & Pensioned & $110(31.1)$ & 81 (73.6) & $29(26.4)$ \\
\hline & Unemployed & $24(6.8)$ & $20(83.3)$ & $4(16.7)$ \\
\hline \multirow[t]{4}{*}{ Marital status } & Married & $248(70.3)$ & $188(75.8)$ & $60(24.2)$ \\
\hline & Never married & $31(8.8)$ & $22(71.0)$ & $9(29.0)$ \\
\hline & Widowed & $34(9.6)$ & $23(67.6)$ & II (32.4) \\
\hline & Divorced & $40(11.3)$ & $31(77.5)$ & $9(22.5)$ \\
\hline \multirow[t]{4}{*}{ Average monthly income } & $<1001$ & $79(22.4)$ & $63(79.7)$ & $16(20.3)$ \\
\hline & $100 \mid-2500$ & $95(26.9)$ & $63(66.3)$ & $32(33.7)$ \\
\hline & $250 I-4000$ & $98(27.8)$ & $77(78.6)$ & $2 \mathrm{I}(2 \mathrm{I} .4)$ \\
\hline & $>4001$ & $81(22.9)$ & $61(75.3)$ & $20(24.7)$ \\
\hline
\end{tabular}

CD4 counts, duration on ART, BMI and high blood pressure, dietary diversity score (DDS) were associated with dyslipidemia (p-value $<0.25$ ).

\section{Multivariate Logistic Regression Analysis}

Variable of interest and those which had a P value of less than 0.25 were fit for multiple logits. Accordingly, sex, age, educational status, occupational status, marital status, income level, WHO clinical stage, ragmen category, baseline CD4 count, current CD4 count, duration on ART, recent viral loud, cigarette smoking, alcohol consummation, chat chewing, dietary diversity score, physical activity, BECK depression score, BMI, blood pressure and FBS were included. The analysis showed that sex, educational status, WHO clinical stage, duration on ART and BMI had a significant association with Dyslipidemia at $\mathrm{p}$-value $<0.05$.
The odds of dyslipidemia were nearly twice and half (AOR: 2.38[95\% CI: 1.07, 5.28]) among females compared with male participants. Similarly, compared to those who

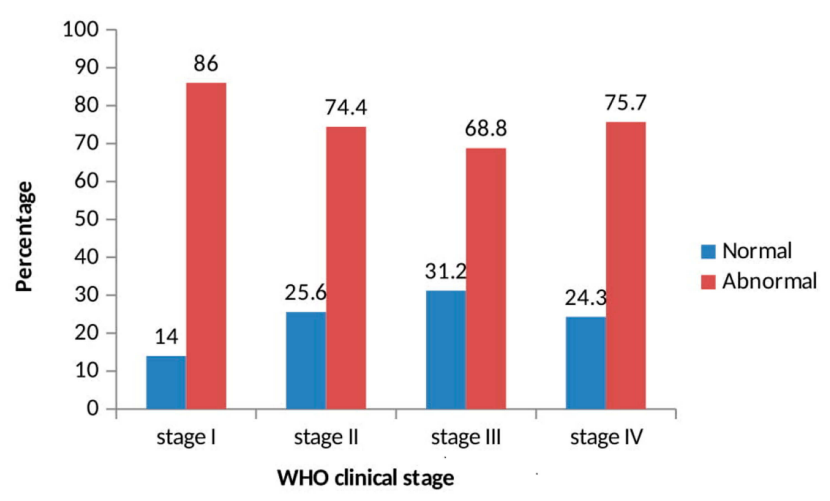

Figure I Prevalence of dyslipidemia in relation to WHO clinical stage in armed force comprehensive and specialized hospital, Addis Ababa, Ethiopia, 2018. 
Table 2 Behavioral and Metabolic Characteristics of Study Subjects Among Patients Living with HIV/AIDS at Armed Force Comprehensive and Specialized Hospital, Addis Ababa, Ethiopia Between March and April $2018(n=353)$

\begin{tabular}{|c|c|c|c|c|}
\hline \multirow[t]{2}{*}{ Variables } & \multirow[t]{2}{*}{ Category } & \multirow[t]{2}{*}{ Total } & \multicolumn{2}{|c|}{ Dyslipidemia } \\
\hline & & & Yes (\%) & No (\%) \\
\hline \multirow[t]{2}{*}{ Currently smoking status } & Yes & $13(3.7)$ & $10(76.9)$ & $3(23.1)$ \\
\hline & No & $340(96.3)$ & $254(73.5)$ & $86(25.3)$ \\
\hline \multirow[t]{2}{*}{ Alcohol consummation status } & Yes & $131(37.1)$ & $97(74.0)$ & $34(26.0)$ \\
\hline & No & $222(62.9)$ & $167(75.2)$ & $55(24.8)$ \\
\hline \multirow[t]{2}{*}{ Chat chewing status } & Yes & $12(3.4)$ & $10(83.3)$ & $2(16.7)$ \\
\hline & No & $34 I(96.6)$ & $254(74.5)$ & $87(25.5)$ \\
\hline \multirow[t]{2}{*}{ Physical activity } & Yes & $244(69.12)$ & |8| (74.2) & $63(25.8)$ \\
\hline & No & $109(30.88)$ & $83(76.1)$ & $26(23.9)$ \\
\hline \multirow[t]{2}{*}{ Dietary diversity score } & Diversified & $195(55.2)$ & 151 (77.4) & $44(22.6)$ \\
\hline & Undiversified & I58 (44.8) & $113(7 \mid .5)$ & $45(28.5)$ \\
\hline \multirow[t]{3}{*}{ Depression status } & Minimal & $203(57.5)$ & 151 (74.4) & $52(25.6)$ \\
\hline & Mild & $85(24.1)$ & $61(71.8)$ & $24(28.2)$ \\
\hline & Moderate/sever & $65(18.4)$ & $52(80.0)$ & $13(20.0)$ \\
\hline \multirow[t]{2}{*}{ Abdominal/central obesity } & Normal & $166(47.0)$ & $112(67.5)$ & $54(32.5)$ \\
\hline & Abnormal & $187(53.0)$ & $152(81.3)$ & $35(18.7)$ \\
\hline \multirow[t]{4}{*}{ Body mass index } & $<18.5 \mathrm{~kg} / \mathrm{m}^{2}$ & $48(13.6)$ & $26(54.2)$ & $22(45.8)$ \\
\hline & $18.5-24.99 \mathrm{~kg} / \mathrm{m}^{2}$ & $198(56.1)$ & $150(75.8)$ & $48(24.2)$ \\
\hline & $25-30 \mathrm{~kg} / \mathrm{m}^{2}$ & $80(22.7)$ & $63(78.7)$ & $17(2 \mid .3)$ \\
\hline & $>30 \mathrm{~kg} / \mathrm{m}^{2}$ & $27(7.6)$ & $25(92.6)$ & $2(7.4)$ \\
\hline \multirow[t]{2}{*}{ Blood pressure } & Normal & $218(61.8)$ & I55 (7I.I) & $63(28.9)$ \\
\hline & Abnormal & 135 (38.2) & 109 (80.7) & $26(19.3)$ \\
\hline
\end{tabular}

attended college level of education, who did not have formal education $(\mathrm{AOR}=0.19[95 \% \mathrm{CI}: 0.05,0.66])$ and having primary/secondary education level $(\mathrm{AOR}=0.33$ [95\% CI:0.16, 0.66]) showed lower odds to develop dyslipidemia. The odds of dyslipidemia were lower among women who had baseline WHO clinical stage II and clinical

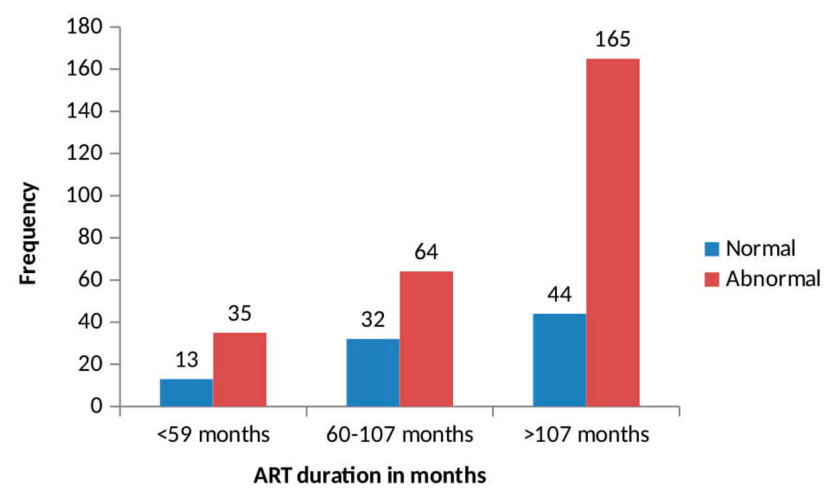

Figure 2 Prevalence of dyslipidemia in relation to duration on ART per months in armed force comprehensive and specialized hospital, Addis Ababa, Ethiopia, 2018. stage III by $65 \%$ (AOR $=0.35[95 \%$ CI:0.14,0.92]) and $75 \%$ (AOR $=0.25[95 \%$ CI: 0.10, 0.64], respectively, when compared with WHO stage I. As well, when duration on ART increase by 1 month, the risk of dyslipidemia increased by $1 \%$ (AOR $=1.01[95 \%$ CI: 1.00,1.22]). Similarly, when BMI increases by $1 \mathrm{~kg} / \mathrm{m}^{2}$, the risk of dyslipidemia increased by $13 \%(\mathrm{AOR}=1.13[95 \% \mathrm{CI}: 1.04,1.22])$. (Table 3$)$

\section{Discussion}

The present study assessed the prevalence and associated factors of dyslipidemia in HIV-infected adults receiving ART at Armed Force Comprehensive and Specialized Hospital, Addis Ababa, Ethiopia.

The overall prevalence of dyslipidemia was $74.8 \%$ : $95 \%$ CI: (70.3\%,79.3\%). It was comparable with other findings from Tanzania $(73.0 \%, 77.5 \%),{ }^{22,23}$ Cameroon $(70.2 \%),{ }^{24}$ China (75.6\%), ${ }^{25}$ and Brazil (78.9\%) ${ }^{20}$ but lower than the studies conducted from Addis Ababa (80.0\%), ${ }^{12}$ Hawassa $(82.3 \%),{ }^{11}$ Kenya $(79.6 \%),{ }^{25}$ and South Africa $(90.0 \%),{ }^{7}$ but, it was higher than studies conducted in Addis Ababa 
Table 3 Multivariate Logistic Regression Analysis Among Patients Living with HIVIAIDS at Armed Force Comprehensive and Specialized Hospital, Addis Ababa, Ethiopia Between March and April $2018(n=353)$

\begin{tabular}{|c|c|c|c|c|}
\hline Variables & Category & Crude OR/Beta (95\% C.I) & Adjusted OR/Beta (95\% C.I) & P-value \\
\hline \multirow[t]{2}{*}{ Sex } & Female & $1.56(0.95,2.57)$ & $2.38(1.07,5.28)$ & $0.03 *$ \\
\hline & Male & 1.00 & 1.00 & \\
\hline \multicolumn{2}{|l|}{ Age } & $1.03(1.00,1.06)$ & $1.04(1.00,1.08)$ & 0.074 \\
\hline \multirow[t]{3}{*}{ Educational status } & Illiterate & $0.32(0.11,0.93)$ & $0.19(0.05,0.66)$ & $0.009 *$ \\
\hline & Primary/secondary & $0.42(0.23,0.77)$ & $0.33(0.16,0.66)$ & $0.002 *$ \\
\hline & College and above & 1.00 & 1.00 & \\
\hline \multirow[t]{5}{*}{ Occupational status } & House wife & 1.00 & 1.00 & \\
\hline & Employer & I. $15(0.56,2.35)$ & $0.34(0.08,1.55)$ & 0.163 \\
\hline & Merchant & $1.46(0.41,5.16)$ & $0.52(0.13,2.04)$ & 0.348 \\
\hline & Pensioners & $1.09(0.51,2.30)$ & $0.38(0.06,2.4 I)$ & 0.304 \\
\hline & Unemployed & $1.94(0.54,6.7 I)$ & $0.62(0.15,2.55)$ & 0.506 \\
\hline \multirow[t]{4}{*}{ Marital status } & Married & 1.00 & 1.00 & \\
\hline & Never married & $0.78(0.34,1.79)$ & I.0I $(0.37,2.73)$ & 0.983 \\
\hline & Widowed & $0.67(0.31,1.45)$ & $0.42(0.15,1.15)$ & 0.09 \\
\hline & Divorced & I. $10(0.49,2.44)$ & $0.79(0.3,2.12)$ & 0.65 \\
\hline \multicolumn{2}{|l|}{ Average monthly income } & $1.000(1.00,1.00)$ & $1.00(100,100)$ & 0.77 \\
\hline \multirow[t]{4}{*}{ WHO clinical stage } & Stage I & 1.00 & 1.00 & \\
\hline & Stage II & $0.47(0.20,1.1 \mathrm{I})$ & $0.35(0.14,0.92)$ & $0.033^{*}$ \\
\hline & Stage III & $0.36(0.15,0.84)$ & $0.25(0.10,0.64)$ & $0.00 *$ \\
\hline & Stage IV & $0.5 \mathrm{I}(0.20, \mathrm{I} .28)$ & $0.49(0.17,1.40)$ & 0.185 \\
\hline \multicolumn{2}{|l|}{ Base line CD4 count } & $1.001(0.99,1.003)$ & $1.00(0.98,1.00)$ & 0.323 \\
\hline \multicolumn{2}{|l|}{ Current CD4 count } & $1.001(1.00,1.002)$ & $1.00(0.97,1.00)$ & 0.775 \\
\hline \multicolumn{2}{|l|}{ Duration on ART } & $1.007(1.00,1.014)$ & $1.01(1.00,102)$ & $0.019 *$ \\
\hline \multicolumn{2}{|l|}{ Recent Viral load } & $1.000(1.00,100)$ & $1.00(0.96,1.00)$ & 0.09 \\
\hline \multirow[t]{6}{*}{ Type of regimen } & AZT,3TC, NPV & 1.00 & 1.00 & \\
\hline & AZT,3TC, EFV & $0.72(0.28,1.83)$ & $0.33(0.09,1.29)$ & 0.112 \\
\hline & TDF,3TC, EFV & $1.12(0.59,2.11)$ & $0.28(0.06,1.26)$ & 0.097 \\
\hline & TDF,3TC, NPV & I.3I $(0.5 \mathrm{I}, 3.37)$ & $0.58(0.16,2.07)$ & 0.401 \\
\hline & ABC,3TC, ATZ & $0.72(0.19,2.68)$ & $0.51 \quad(0.12,2.22)$ & 0.365 \\
\hline & $\mathrm{ABC}, 3 \mathrm{TC}, \mathrm{ATV} / \mathrm{r}$ & $1.53(0.45,5.16)$ & $0.56(0.09,3.58)$ & 0.539 \\
\hline \multirow[t]{2}{*}{ Cigarette smoking } & Yes & $1.13(0.30,4.12)$ & $\mathrm{I} .64(0.3 \mathrm{I}, 8.78)$ & $0.56 \mathrm{I}$ \\
\hline & No & 1.00 & 1.00 & \\
\hline \multirow[t]{2}{*}{ Alcohol consummation } & Yes & $0.94(0.57,1.54)$ & $0.82(0.46, I .46)$ & 0.496 \\
\hline & No & 1.00 & 1.00 & \\
\hline \multirow[t]{2}{*}{ Physical activity } & Yes & 1.00 & 1.00 & \\
\hline & No & $0.90(0.53-1.52)$ & $\mathrm{I}, \mathrm{I} 6(0.63,2.16)$ & 0.633 \\
\hline \multirow[t]{2}{*}{ Khat chewing } & Yes & I.7। $(0.37,7.97)$ & $1.6(0.23,11.10)$ & 0.634 \\
\hline & No & 1.00 & 1.00 & \\
\hline \multirow[t]{2}{*}{ DDS status } & Diversified & 1.00 & 1.00 & \\
\hline & Undiversified & $0.73(0.45,1.18)$ & $0.88(0.50,1.55)$ & 0.665 \\
\hline \multirow[t]{3}{*}{ Depression status } & Minimal & 1.00 & 1.00 & \\
\hline & Mild & $0.87(0.50,1.54)$ & $0.87(0.44,1.72)$ & 0.697 \\
\hline & Moderate/sever & $1.38(0.69,2.73)$ & $1.29(0.57,2.92)$ & 0.538 \\
\hline
\end{tabular}


Table 3 (Continued).

\begin{tabular}{|l|l|l|l|l|}
\hline Variables & Category & Crude OR/Beta (95\% C.I) & Adjusted OR/Beta (95\% C.I) & P-value \\
\hline Blood pressure & Normal & 1.00 & 1.00 & \\
& Abnormal & $1.70(1.02,2.86)$ & $1.30(0.68,2.48)$ & 0.436 \\
\hline $\begin{array}{l}\text { Body mass index } \\
\text { Fasting blood sugar level }\end{array}$ & $1.13(1.06,1.20)$ & $1.13(1.04,1.22)$ & $0.003^{*}$ \\
0.89 & $1.00(0.98,1.00)$ & 0.89 \\
\hline
\end{tabular}

Notes: *Shows $\mathrm{p}$-value $<0.05$, adjusted, 1.00 , shows reference category Hosmer-Lemeshow test $(\mathrm{p}$-value $=0.062)$.

$(63.6 \%),{ }^{26}$ and Zimbabwe $(60 \%) .{ }^{13}$ This may be due to the difference in socioeconomic characteristics, dietary habit and sample size variation. The direct effects of ART on lipid metabolism, endothelial and adipocyte cell function, and mitochondria have been suggested for altered lipid profiles. ${ }^{4}$

The odds of dyslipidemia were nearly twice and half among females when compared with male participants. This finding was in line with a study done in Tanzania, ${ }^{23}$ but not in line with studies done in South Africa, ${ }^{7}$ Cameroon, ${ }^{27}$ and Latin America. $^{28}$ The discrepancy is more likely due to gender-related exercise habits and biologic differences in males and females in handling ART adverse outcomes. ${ }^{20}$

In addition, the consequence of the increased life expectancy of PLHIV results from the growing number of women living with HIV going through the physical as well as hormonal changes of the menopausal transition. Despite the viral suppression and immune recovery promoted by modern treatment, aging, together with prolonged exposure to antiretroviral drugs, may increase the risk of dyslipidemia in women. ${ }^{29}$

Variability in the relationship between the WHO clinical stage and dyslipidemia existed in this study. While being in stage II and III had a better effect on dyslipidemia compared to stage 1 , but there was no association between stage 4 and dyslipidemia. It is known that HIV has a wild effect on lipid metabolism which is not predictable.

BMI was found to have a positive association with dyslipidemia, an increase in BMI by $1 \mathrm{~kg} / \mathrm{m}^{2}$, the odds of dyslipidemia increase by $13 \%$. This finding is similar to studies conducted from south Ethiopia, ${ }^{11}$ Uganda, $^{30}$ Tanzania, ${ }^{23}$ South Africa, ${ }^{7}$ Cameroon, ${ }^{27}$ and Korea. ${ }^{31}$ The observed association can be expounded by the occurrence of ART-associated lipodystrophy with an increase in visceral fat accompanied by loss of peripheral subcutaneous fat. ${ }^{7,22}$ The pathogenesis of lipodystrophy in people living with HIV is multifactorial and still not fully understood. This disease is most likely a result of the interaction between antiretroviral therapy, virus infection, genetic factors, and the lifestyle of the individual. ${ }^{32}$
In addition, duration on ART was significantly associated with dyslipidemia, an increase in the duration of ART by one month, the odds of dyslipidemia increased by $1 \%$. Many studies also reported a similar finding. ${ }^{33,34}$ This positive association could be explained by the possible interaction of aging, HIV infectious process and the drug adverse outcome on lipid metabolism. ${ }^{23}$

Moreover, the study also showed that lower odds of dyslipidemia were found among subjects who have attained a lower level of education (no formal education, primary and secondary education) compared to those who attained college and above. This finding was in line with the systematic review done in the United Kingdom, ${ }^{35}$ and Japan, $^{36}$ but contradicts with many studies. ${ }^{37,38}$ This may be due to lifestyle differences.

Contrary to the study in Tanzania, aged patients were not associated with dyslipidemia in this study. Similarly, there was no association between depression status and dyslipidemia. But, the fact is as a patient depressed, it becomes inactivate (being sedentary in their lifestyle) because of this is prone to obesity, as a result, it leads to dyslipidemia.

Moreover, markers of advanced disease stage such as low CD4 were not associated with dyslipidemia. However, studies in China, ${ }^{39}$ Cameroon, ${ }^{40}$ and Tanzania ${ }^{23}$ showed a strong association between CD4 count and the likelihood of abnormal lipid metabolism.

In this study, there was no significant association between dyslipidemia and ART regimens in this study. These observed differences between the findings of our study and the latter study may be due to the inclusion of $\mathrm{d} 4 \mathrm{~T}$ in the latter study could be the main cause of increased serum lipid levels. ${ }^{22}$ Assessing all lipoproteins by using a laboratory was the strength of this study.

In interpreting our results, one should be noted the fact that our proportion could have been underestimated due to the exclusion made for people who were taken anti lipid drugs. The rational for the exclusion was to avoid error which could result from unverifiable patients own report 
about their past dyslipidemia status as the lipid profile measurements is not part of routine care in the institution.

\section{Conclusion}

There was a high prevalence of dyslipidemia among study participants. Being female, low level of educational status, being in WHO stage II and III, duration on ART and increased BMI were associated with dyslipidemia among patients living with HIV/AIDS. Therefore, intervention strategies addressing dietary, lifestyle and behavioral factors should be enhanced especially for females, those who take ART for longer periods, patients with early WHO clinical stage, highly educated subjects and those who had increased body mass index. The high level of dyslipidemia in this study might lead to high morbidity and mortality towards NCD. Therefore, lipid profile measurements at baseline need to be part of routine care to avert the devastating effect of dyslipidemia.

\section{Abbreviations}

ART, Antiretroviral treatment; ARV, Antiretroviral; BMI, Body mass index; CRABP, Cellular retinoic acid binding protein; CVD, Cardiovascular disease; DM, Diabetes Mellitus; EFV, Efavirenz; ER, Endoplasmic reticulum; FPG, Fasting plasma glucose; Gm/dl, Gram per deciliter; HDL, High-density lipoprotein; HIV/AIDS, Human immune deficiency virus/Acquired immune deficiency syndrome; LDL, Low-density lipoprotein; LRP, LDL receptor-related protein; MI, Myocardial Infarction; NCD, Non-communicable diseases; N/NRTI, Nucleoside/Nucleotide reverse Transcriptase Inhibitor; NNRTI, Non-Nucleoside Reverse Transcriptase Inhibitor; NVP, Nevirapine; OI, Opportunistic Infections; PI, Protease inhibiter; PLWHA, People living with HIV/AIDS; RVI, Retroviral infections; SREBP, sterol regulatory element-binding proteins; TC, Total cholesterol; TG, Triglycerides; UNAIDS, United Nation joint program on HIV/AIDS; VLDL, Very-Low-density lipoprotein; WHO, World Health Organization.

\section{Data Sharing Statement}

The dataset used for this study cannot be shared and in the future, interested parties may request the approval to access the data by writing to Jimma University Institutional Review Board.

\section{Acknowledgments}

We would like to thank Jimma University, Institute of Health, and Armed Force Comprehensive and Specialized Hospital for funding and sponsoring this study. The authors would also like to thank data collectors and study participants.

\section{Author Contributions}

Adnan Kemal conceived the research idea, conducted the data collection, data analysis, and data interpretation, wrote and reviewed the paper. KalkidanHassen and Melese Sinaga Teshome reviewed and approved the final paper. Mohammed Ahmed, MesertMolla and Jemmal Mohammed reviewed the paper and Tabarak Malik drafted, and finally approved the manuscript. Melese Sinaga Teshome; the corresponding author had the responsibility to submit the manuscript for publication. All authors contributed to data analysis, drafting or revising the article, gave final approval of the version to be published, and agree to be accountable for all aspects of the work.

\section{Funding}

The study was fully funded by Jimma University, Institute of Health, and Faculty of Public Health and Armed Forces Comprehensive and Specialized Hospital.

\section{Disclosure}

We confirm that this research is our original paper and that there is no conflict of interest in this work.

\section{References}

1. Living P, Virus HI, Syndrome AI. Global fact sheet: HIV/AIDS I. HIV/ AIDS Basics. 1981;1-20.

2. Kharsany ABM, Karim QA. HIV infection and AIDS in sub-Saharan Africa: current status. Open AIDS j. 2016;10(1):34-48. doi:10.2174/ 1874613601610010034

3. Mangili A, Wanke C, Mangili A. Dyslipidemia in HIV infection. Future Lipidology. 2017;875(December):719.

4. Beth S. World's largest Science, Technology \& Medicine Open Access book publisher Highly Active Antiretroviral Therapy (HAART) and metabolic complications. 2011.

5. Chelsea N, McMahon EB. Health of HIV Infected People Food, Nutrition and Lifestyle with Antiretroviral Drugs. Watson RR, editor: Academic Press: 2015. 441-469 p.

6. Grunfeld C, Kotler DP, Arnett DK, et al. Contribution of metabolic and anthropometric abnormalities to cardiovascular disease risk factors dissecting the effect of HIV alone: metabolic. Circulation. 2008;118(2):e20-e28.

7. Dave JA, Levitt NS, Ross IL, Lacerda M, Maartens G, Blom D. Antiretroviral therapy increases the prevalence of dyslipidemia in South African HIV-infected patients. PLoS One. 2016;11:1-13.

8. Dimala CA, Blencowe H. Association between highly active antiretroviral therapy and selected cardiovascular disease risk factors in subSaharan Africa: a systematic review and meta-analysis protocol. $B M J$ open. 2017;7:1-8.

9. Rajikan NH. Metabolic abnormalities in HIV-infected populations without or with antiretroviral therapy (ART). In:Health HIV Infected People. Academic Press.17-49. 
10. Overview T, Chd M, Factors R, et al. Guideline for the diagnosis and management of dyslipidemia for adults $>18$ years of age treatment overview of dyslipidemia major CHD isk factors (Exclusive of LDLC). 2008;1-10.

11. Tadewos A, Addis Z, Ambachew H, Banerjee S. Prevalence of dyslipidemia among HIV-infected patients using first-line highly active antiretroviral therapy in Southern Ethiopia: a cross-sectional comparative group study. AIDS Res Ther. 2012;9(1):1. doi:10.1186/ 1742-6405-9-31

12. Belay E, Seifu D, Amogne W, Kibret KT. Lipid profile derangements among human immunodeficiency virus infected adults receiving first line anti-retroviral therapy in tikur anbesa specialized hospital, addis ababa, ethiopia: comparative cross-sectional. JAIDS Clin Res. 2014;5:8.

13. Zhou DT, Nehumba D, Oktedalen O, et al. Changes in lipid profiles of HIV + adults over nine months at a harare HIV clinic: a longitudinal study. Biochem Res Int. 2016;2016(April):2004.

14. Kuti MA, Adesina OA, Awolude OA, et al. Dyslipidemia in ARTnaive HIV-infected persons in Nigeria - implications for care. J Int Assoc Providers AIDS Care. 2015;14(4):355-359.

15. Ceccato MGB, Bonolo PF, Neto AIS, Araújo FS, Freitas MIF. Antiretroviral therapy-associated dyslipidemia in patients from a reference center in Brazil. Braz J Med Biol Res. 2011;44 (November):1177-1183.

16. Nery MW. Dyslipidemia in AIDS patients on highly active antiretroviral therapy. Braz J Infect Dis. 2011;15(2):151-155.

17. Cristina C, Mendicino P, Braga LP, De CAM, Drew M, Guimarães C. Short communication high incidence of hypertriglyceridemia in a Brazilian cohort of people living with HIV/AIDS undergoing antiretroviral treatment in Belo Horizonte, 2001-2010. Rev Soc Bras Med Trop. 2016;49(August):758-762.

18. Tsai F, Cheng C, Lai C, Wu Y. Effect of antiretroviral therapy use and adherence on the risk of hyperlipidemia among HIV-infected patients, in the highly active antiretroviral therapy era. Oncotarget. 2017;8 (63):106369-106381.

19. WHO. The WHO STEPwise Approach to Chronic Disease Risk Factor Surveillance. Geneva: World Health Organization; 2005.

20. Limas TG, Pinto GDA, Marcato LM, Coelho DR. Major article analysis of the prevalence of dyslipidemia in individuals with HIV and its association with antiretroviral therapy. Rev Soc Bras Med Trop. 2014;47(October):547-551.

21. Lemogoum D, Seedat YK, Fattah A, et al. Recommendations for prevention, diagnosis and management of hypertension and cardiovascular risk factors in sub-Saharan Africa Mohamed Belhocine and Jean Paul Degaute, on behalf of the International Forum for Hypertension Control and Prevention in Africa (IFHA). $J$ Hypertens. 2003;21(11):1993-2000.

22. Liu E, Armstrong C, Spiegelman D, et al. First-line antiretroviral therapy and changes in lipid levels over 3 years among HIV-infected adults in Tanzania. Clin Infect Dis. 2018;56(January):1820-1828.

23. Ombeni W, Kamuhabwa AR. Lipid profile in HIV-infected patients using first-line antiretroviral drugs. J Int Assoc Providers AIDS Care. 2016;15(2):164-171.

24. Bekolo CE, Nguena MB, Ewane L, Bekoule PS, Kollo B. The lipid profile of HIV-infected patients receiving antiretroviral therapy in a rural Cameroonian population. BMC Public Health. 2014;14(1). doi:10.1186/1471-2458-14-236

HIV/AIDS - Research and Palliative Care

\section{Publish your work in this journal}

HIV/AIDS - Research and Palliative Care is an international, peerreviewed open-access journal focusing on advances in research in HIV, its clinical progression and management options including antiviral treatment, palliative care and public healthcare policies to
25. Njoroge A, Farquhar C, Guthrie BL. Prevalence and correlates of dyslipidemia among HIV-1 infected and HIV-1 uninfected individuals in Nairobi. Kenya Anne Njoroge Chair. 2014.

26. Bayenes HW, Ahmed MK, Shenkute TY, Ayenew YA, Bimerew LG. Prevalence and predictors of dyslipidemia on HAART and HAART naive HIV positive persons in Defense Hospital. Am J Health Res. 2014;2(5):303-309.

27. Nsagha DS, Weledji EP, Jules N, et al. Highly active antiretroviral therapy and dyslipidemia in people living with HIV/AIDS in fako division, south west region of Cameroon. BMC Cardiovasc Disord. 2015;15:1-8.

28. Cahn A, Ca A, Rosales A, et al. ORIGINAL Metabolic profile and cardiovascular risk factors among Latin American HIV-infected patients receiving HAART. Braz J Infect Dis. 2010;14(2):158-166.

29. Bull FC, Maslin TS, Armstrong T. Global Physical Activity Questionnaire (GPAQ): nine country reliability and validity study. $J$ Phys Act Health. 2009;6:790-804.

30. Kazooba P, Kasamba I, Munderi P. Cardiometabolic risk among HIVPOSITIVE Ugandan adults: prevalence, predictors and effect of longterm antiretroviral therapy. Pan Afr Med J. 2017;8688:1-14.

31. Oh DH, Ahn JY, Il KS, et al. Metabolic complications among Korean patients with HIV infection: the Korea HIV/AIDS cohort study. $J$ Korean Med Sci. 2017;32(8):1268. doi:10.3346/jkms.2017.32.8.1268

32. Basqueroto L, Justina D, Luiz MC, Maurici R. Prevalence and factors associated with lipodystrophy in AIDS patients. Rev Soc Bras Med Trop. 2014;47(1):30-37.

33. Limas TGD, Pinto GDA, Marcato LM, Coelho DR. Analysis of the prevalence of dyslipidemia in individuals with HIV and its association with antiretroviral therapy. Rev Soc Bras Med Trop. 2014;47 (5):547-551. doi:10.1590/0037-8682-0128-2014

34. Nsagha DS, Weledji EP, Assob NJC. et al. Highly active antiretroviral therapy and dyslipidemia in people living with HIV/AIDS in Fako Division, South West Region of Cameroon. BMC Cardiovasc Disord. 2015;15(95).

35. Dinsa GD, Goryakin Y, Fumagalli E, Suhrcke M. Obesity and socioeconomic status in developing countries: a systematic review. Obesity Rev. 2012;13(11):1067-1079.

36. Murakami K, Ohkubo T, Hashimoto H. Distinct association between educational attainment and overweight/obesity in unmarried and married women: evidence from a population-based study in Japan. $B M C$ Public Health. 2017;17(1):1-9. doi:10.1186/s12889-017-4912-5

37. Ataro $\mathrm{Z}$ and Ashenafi W. Metabolic syndrome and associated factors among adult HIV positive people on antiretroviral therapy in Jugal hospital, Harar, Eastern Ethiopia. East Afr J Health Biomed Sci. 2020;4(1):13-24.

38. Gebrie A, Sisay M, Gebru T. Dyslipidemia in HIV/AIDS infected patients on follow up at referral hospitals of Northwest Ethiopia: a laboratory-based cross-sectional study. Obesity Med. 2020:100217. doi:10.1016/j.obmed.2020.100217

39. Shen Y, Wang J, Wang Z, et al. Prevalence of dyslipidemia among antiretroviral-naive HIV-infected individuals in China. Medicine. 2015;94(48):1-8.

40. Walter E, Yone P, Betyoumin AF, et al. First-line antiretroviral therapy and dyslipidemia in people living with HIV-1 in Cameroon: a cross-sectional study. AIDS Res Ther. 2011;8(1):1-8. control viral spread. The manuscript management system is completely online and includes a very quick and fair peer-review system, which is all easy to use. Visit http://www.dovepress.com/testimonials.php to read real quotes from published authors. 